\title{
Oxidation of Rhodium(I) by Hydroxamic Acids. Synthesis, Structure, and Electrochemical Properties of Bis(hydroxamate) Complexes of Rhodium(III)
}

\author{
Anindya Das, ${ }^{\text {1a }}$ Falguni Basuli, ${ }^{1 \text { a }}$ Shie-Ming Peng, ${ }^{1 \mathrm{~b}}$ and Samaresh Bhattacharya ${ }^{\star, 1 a}$ \\ Department of Chemistry, Inorganic Chemistry Section, Jadavpur University, \\ Kolkata 700 032, India, and Department of Chemistry, National Taiwan University, \\ Taipei, Taiwan, Republic of China
}

Received July 2, 2001

\section{Introduction}

There has been considerable interest in the coordination chemistry of the hydroxamic acids (1), because of their relevance in the physiological systems in general $^{2}$ and because of their siderophoric activities in microbial transport of iron $^{3}$ and their theraputic applications in particular. ${ }^{4}$ Hydroxamic acids are known to bind to metal ions usually as a bidentate $\mathrm{O}, \mathrm{O}$-donor forming a five-membered chelate ring (2). ${ }^{5}$ However, we have recently observed an interesting chemical transformation of $\mathrm{N}$-phenylbenzohydroxamic acids into their corresponding amides, brought about during their reaction with $\left[\mathrm{Os}(\mathrm{bpy})_{2} \mathrm{Br}_{2}\right]$, whereby the amides coordinate to osmium(III) as dianionic C,N-donors (3). ${ }^{6}$ This has encouraged us to explore the interaction of the hydroxamic acids with other transition metal ions, preferably in their low oxidation states. For this study we selected rhodium(I) as the low-valent metal ion and $N$-phenylbenzohydroxamic acids as ligand. It may be mentioned here that though the chemistry of hydroxamate complexes of many transition metals has received considerable attention, ${ }^{2}$ that of rhodium hydroxamates appears to remain completely unexplored. As the source of rhodium(I), the Wilkinson's catalyst, viz. [Rh$\left(\mathrm{PPh}_{3}\right)_{3} \mathrm{Cl}$, was chosen because of its well-known ability to

* Corresponding author. E-mail: samaresh_b@hotmail.com.

(1) (a) Jadavpur University. (b) National Taiwan University.

(2) (a) Mizukami, S.; Nagaka, K. Coord. Chem. Rev. 1968, 3, 267. (b) Chatterjee, B. Coord. Chem. Rev. 1978, 26, 281. (c) Kehl, H., Ed. Chemistry and Biology of hydroxamic Acids; S. Karger: New York, 1982. (d) Crumbliss, A. L. Coord. Chem. Rev. 1990, 105, 155. (e) Kurzak, B.; Kozlowski, H.; Farkas, E. Coord. Chem. Rev. 1992, 114 169. (f) Marmion, C. J.; Murphy, T.; Docherty, J. R.; Noian, K. B. Chem. Commun. 2000, 1153. (g) Farkas, E.; Enyedy, E. A.; Zekany, L.; Deak, G. J. Inorg. Biochem. 2001, 83, 107.

(3) Brown, D. A.; Chidambaram, M. V. In Metal Ions in Biological Systems; Sigel, H., Ed.; Marcel Dekker Inc.: New York, 1982; Vol. 14.

(4) (a) Hase, J.; Kobashi, K. J. Biochemistry (Tokyo) 1967, 62, 293. (b) Fishbein, W. N.; Strecter, C. L.; Daly, J. E. J. Pharmacol. Exp. Ther. 1973, 186, 173.

(5) (a) Zalkin, A.; Forrester, J. D.; Templeton, D. H. J. Am. Chem. Soc. 1966, 88, 1810. (b) Poling, M.; Vander Helm, D. Abstracts, American Crystallographic Association; Spring Meeting, Berkeley, CA, 1974; Q-7, p 111.

(6) Das, A.; Basuli, F.; Falvello, L. R.; Bhattacharya, S. Inorg. Chem. 2001, 40, 4085 .

440 Inorganic Chemistry, Vol. 41, No. 2, 2002 bring about catalytic transformation of organic molecules, ${ }^{7}$ as well as its efficiency as a synthon for the preparation of mixed-ligand octahedral complexes of rhodium(III) via oxidative addition of incoming ligands. ${ }^{8}$ Reaction of the $N$-phenylbenzohydroxamic acids with $\left[\mathrm{Rh}\left(\mathrm{PPh}_{3}\right)_{3} \mathrm{Cl}\right]$ afforded a family of bis(hydroxamate) complexes of rhodium(III) along with the corresponding amides as the byproduct. The chemistry of the bis(hydroxamate) complexes of rhodium(III) is reported here with special reference to their synthesis, structure, and electrochemical properties.<smiles>[R]C(=O)N([R2])O</smiles>

1

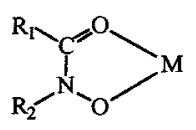

2

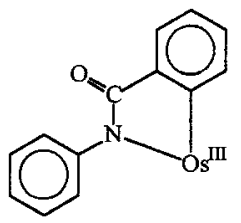

3

\section{Experimental Section}

Materials. Rhodium trichloride was obtained from Johnson Matthey, and triphenylphosphine was purchased from Loba Chemie, Mumbai, India. [ $\left.\mathrm{Rh}\left(\mathrm{PPh}_{3}\right)_{3} \mathrm{Cl}\right]$ was synthesized by following a reported procedure. ${ }^{9}$ 4-Nitrobenzene, 1-chloro-4-nitrobenzene, and 4-nitrotoluene were purchased from Loba Chemie, Mumbai, India, and were converted to the corresponding hydroxylamines by following a literature method. ${ }^{10}$ Benzoyl chloride, 4-nitrobenzoyl chloride, and 4-chlorobenzoyl chloride were purchased from Eastgate, Whiteland, Morecambe, England. The hydroxamic acids were prepared by acylation of the hydroxylamines with the acid chlorides by following a published procedure. ${ }^{11}$ Purification of acetonitrile and preparation of tetrabutylammonium perchlorate (TBAP) for electrochemical work were performed as reported in

(7) Jardine, F. H. Prog. Inorg. Chem. 1981, 28, 63.

(8) (a) Dutta, S.; Peng, S. M.; Bhattacharya, S. Inorg. Chem. 2000, 39, 2231. (b) Dutta, S.; Peng, S. M.; Bhattacharya, S. J. Chem. Soc., Dalton Trans. 2000, 4623.

(9) Osborn, J. A.; Wilkinson, G. Inorg. Synth. 1967, 10, 67.

(10) Vogel, A. I. A Text Book of Practical Organic Chemistry, 3rd ed.; ELBS, Longman: Essex, U.K., 1968; p 197.

(11) Hanser, C. R.; Renfrow, W. B., Jr. Organic Syntheses; John Wiley: New York, 1947; Collect. Vol. 2, p 67. 
Table 1. Crystallographic Data for $\left[\mathrm{Rh}\left(\mathrm{PPh}_{3}\right)(\mathrm{H}-\mathrm{H})_{2} \mathrm{Cl}\right] \cdot \mathrm{CH}_{3} \mathrm{CN}$

\begin{tabular}{ll}
\hline empirical formula & $\mathrm{C}_{46} \mathrm{H}_{38} \mathrm{ClN}_{3} \mathrm{O}_{4} \mathrm{PRh}$ \\
$\mathrm{fW}$ & 866.12 \\
space group & monoclinic, $P 2_{1} / n$ \\
$a, \AA$ & $18.729(4)$ \\
$b, \AA$ & $10.268(2)$ \\
$c, \AA$ & $21.389(4)$ \\
$\beta, \mathrm{deg}$ & $90.98(2)$ \\
$V, \AA^{3}$ & $4112.7(14)$ \\
$Z$ & 4 \\
$\lambda, \AA$ & 0.71073 \\
$T, \mathrm{~K}$ & 295 \\
$\mu, \mathrm{mm}^{-1}$ & 0.566 \\
$\mathrm{R}^{a}$ & 0.0437 \\
$\mathrm{wR}^{b}$ & 0.0644 \\
$\mathrm{GOF}^{c}$ & 1.000
\end{tabular}

${ }^{a} \mathrm{R} 1=\sum|| F_{\mathrm{o}}|-| F_{\mathrm{c}}|| / \sum\left|F_{\mathrm{o}}\right|{ }^{b} \mathrm{wR} 2=\left[\sum\left\{w\left(F_{\mathrm{o}}{ }^{2}-F_{\mathrm{c}}{ }^{2}\right)^{2}\right\} / \sum\left\{w\left(F_{\mathrm{o}}{ }^{2}\right)\right\}\right]^{1 / 2}$. ${ }^{c} \mathrm{GOF}=\left[\sum\left(w\left(F_{\mathrm{o}}{ }^{2}-F_{\mathrm{c}}{ }^{2}\right)^{2}\right) /(M-N)\right]^{1 / 2}$, where $M$ is the number of reflections and $N$ is the number of parameters refined.

the literature. ${ }^{12}$ All other chemicals used for the preparative works were of reagent grade and were used without further purification.

Preparations of Complexes. The $\left[\mathrm{Rh}\left(\mathrm{PPh}_{3}\right)\left(\mathrm{R}-\mathrm{R}^{\prime}\right)_{2} \mathrm{Cl}\right]$ complexes were synthesized by following a general procedure. Yields varied in the range of 55-65\%. Specific details are given below for one complex.

$\left[\mathbf{R h}\left(\mathbf{P P h}_{\mathbf{3}}\right)(\mathbf{H}-\mathbf{H})_{\mathbf{2}} \mathbf{C l}\right] . \mathrm{N}$-Phenylbenzohydroxamic acid $(70 \mathrm{mg}$, $0.33 \mathrm{mmol}$ ) was dissolved in benzene $(40 \mathrm{~mL})$, and triethylamine (22 $\mathrm{mg}, 0.22 \mathrm{mmol}$ ) was added to the solution followed by [Rh$\left(\mathrm{PPh}_{3}\right)_{3} \mathrm{Cl}$ ] (100 mg, $\left.0.11 \mathrm{mmol}\right)$. The mixture was then stirred for $12 \mathrm{~h}$ under a dinitrogen atmosphere to produce an orange solution. Upon partial evaporation benzanilide precipitated as a white solid, which was collected by filtration, washed with cold benzene, and dried in air. Evaporation of the filtrate gave a red solid, which was purified by thin-layer chromatography on a silica gel plate, using 10:1 benzene-acetonitrile as the eluant. A yellow band separated which was extracted with acetonitrile. On evaporation of the acetonitrile solution, $\left[\mathrm{Rh}\left(\mathrm{PPh}_{3}\right)(\mathrm{H}-\mathrm{H})_{2} \mathrm{Cl}\right]$ was obtained as a reddish-orange microcrystalline solid. Yield: $56 \%$.

Physical Measurements. Microanalyses $(\mathrm{C}, \mathrm{H}, \mathrm{N})$ were performed using a Perkin-Elmer 240C elemental analyzer. IR spectra were obtained on a Shimadzu FTIR-8300 spectrometer with samples prepared as $\mathrm{KBr}$ pellets. Electronic spectra were recorded on a JASCO V-570 spectrophotometer. Magnetic susceptibilities were measured using a PAR 155 vibrating-sample magnetometer fitted with a Walker scientific L75FBAL magnet. ${ }^{1} \mathrm{H}$ NMR spectra were recorded on a Brucker DRX-500 NMR spectrometer using TMS as the internal standard. Electrochemical measurements were made using a PAR model 273 potentiostat. A platinum-disk working electrode, a platinum wire auxiliary electrode, and an aqueous saturated calomel reference electrode (SCE) were used in a threeelectrode configuration. A RE $0089 \mathrm{X}-\mathrm{Y}$ recorder was used to trace the voltammograms. Electrochemical measurements were made under a dinitrogen atmosphere. All electrochemical data were collected at $298 \mathrm{~K}$ and are uncorrected for junction potentials.

Crystallography of $\left[\mathbf{R h}\left(\mathbf{P P h}_{\mathbf{3}}\right)(\mathbf{H}-\mathbf{H})_{2} \mathbf{C l}\right]$. Single crystals of $\left[\mathrm{Rh}\left(\mathrm{PPh}_{3}\right)(\mathrm{H}-\mathrm{H})_{2} \mathrm{Cl}\right]$ were grown by slow evaporation of an acetonitrile solution of the complex. Selected crystal data and data collection parameters are given in Table 1. Data were collected on a SMART CCD diffractometer using graphite-monochromated Mo $\mathrm{K} \alpha$ radiation $(\lambda=0.71073 \AA$ ) using $\omega$ scans. X-ray data reduction and structure solution and refinement were done using the SHELXS-

(12) (a) Sawyer, D. T.; Roberts, J. L., Jr. Experimental Electrochemistry for Chemists; Wiley: New York, 1974; pp 167-215. (b) Walter, M.; Ramaley, L. Anal. Chem. 1973, 45, 165.
Scheme 1
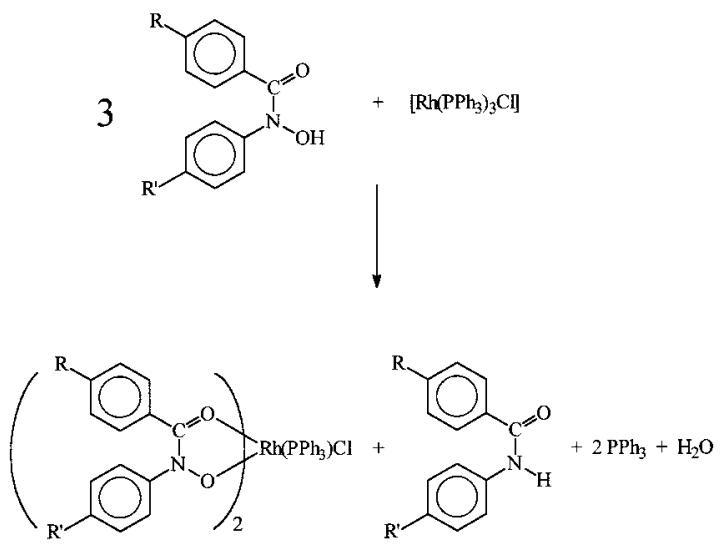

97 and SHELXL-97 programs. ${ }^{13}$ The structure was solved by the direct methods.

\section{Results and Discussion}

Nine hydroxamic acids (4) belonging to the $N$-phenylbenzohydroxamic acid family were used in this study. The ligands are abbreviated in general as $\mathrm{HR}-\mathrm{R}^{\prime}$, where $\mathrm{H}$ stands for the dissociable proton of the NOH group and R and $\mathrm{R}^{\prime}$ stand for the two substituents. The ligands are shown in $\mathbf{4}$. Reaction of these hydroxamic acids with $\left[\mathrm{Rh}\left(\mathrm{PPh}_{3}\right)_{3} \mathrm{Cl}\right]$ in 3:1 mole ratio proceeds smoothly in benzene solution at ambient temperature in the presence of a base to afford bis(hydroxamate) complexes of the type $\left[\mathrm{Rh}\left(\mathrm{PPh}_{3}\right)\left(\mathrm{R}-\mathrm{R}^{\prime}\right)_{2} \mathrm{Cl}\right]$ as well as the corresponding amide. The amides were fully characterized by microanalysis, infrared and ${ }^{1} \mathrm{H}$ NMR spectroscopy, and mass spectral studies. The overall reaction may be represented as shown in Scheme 1. Initial redox reaction between the rhodium(I) center and 1 equiv of the hydroxamic acid seems to have taken place whereby the hydroxamic acid is reduced to its corresponding amide and rhodium(I) is oxidized to rhodium(III). Such oxidizing ability of the hydroxamic acids is documented in the literature. ${ }^{2 \mathrm{~g}, 14}$ We have also experienced one such reaction recently where osmium(II) served as the reducing agent and the reduced amide remained coordinated to the oxidized metal. ${ }^{6}$ However, the amides did not participate in complexation in the present case and hence the amides are obtained as byproduct. The additional 2 equiv of hydroxamic acid subsequently bind to rhodium(III) via dissociation of the $\mathrm{NOH}$ protons to afford the $\left[\mathrm{Rh}\left(\mathrm{PPh}_{3}\right)\left(\mathrm{R}-\mathrm{R}^{\prime}\right)_{2} \mathrm{Cl}\right]$ complexes. It may be mentioned here that if less than 3 equiv of hydroxamic acid is used in the synthetic reaction, the yield of the $\left[R h\left(\mathrm{PPh}_{3}\right)\left(\mathrm{R}-\mathrm{R}^{\prime}\right)_{2^{-}}\right.$ $\mathrm{Cl}$ ] complexes decreases considerably. This is in well accordance with the dual role, viz. the role of a two-electron oxidant and the role of a bidentate $\mathrm{O}, \mathrm{O}-$-donor ligand, played by the hydroxamic acids in the synthetic reaction as illustrated in Scheme 1. Elemental $(\mathrm{C}, \mathrm{H}, \mathrm{N})$ analytical data of the complexes agree well with their compositions.

(13) Sheldrick, G. M. SHELXS-97 and SHELXL-97, Fortran programs for crystal structure solution and refinement; University of Gottingen: Gottingen, Germany, 1997.

(14) (a) Smith, W. L.; Raymond, K. N. Inorg. Nucl. Chem. 1979, 41, 1431. (b) Brown, D. A.; Bogge, H.; Coogan, R.; Doocey, D.; Kemp, T. J.; Muller, A.; Neumann, B. Inorg. Chem. 1996, 35, 1674. 


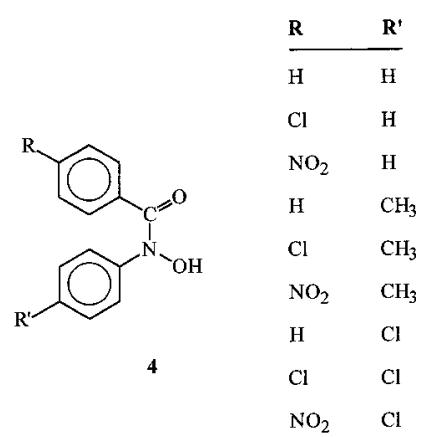

As the hydroxamic acids are unsymmetrical bidentate ligands, the $\left[\mathrm{Rh}\left(\mathrm{PPh}_{3}\right)\left(\mathrm{R}-\mathrm{R}^{\prime}\right)_{2} \mathrm{Cl}\right]$ complexes may exist in six geometrical isomeric forms. To find out the stereochemistry of these complexes, the structure of a representative member of this family, viz. $\left[\mathrm{Rh}\left(\mathrm{PPh}_{3}\right)(\mathrm{H}-\mathrm{H})_{2} \mathrm{Cl}\right]$, was determined by X-ray crystallography. The structure is shown in Figure 1, and selected bond parameters are given in Table 2 . The $N$-phenylbenzohydroxamate ligands are coordinated to rhodium in the usual manner, as bidentate O,O-donor forming five-membered chelate rings with a bite angle of $\sim 80^{\circ}$. The two carbonyl oxygens are mutually cis while the other two $\mathrm{NO}$ oxygens are mutually trans. The $\mathrm{O}_{4} \mathrm{PCl}$ coordination sphere around rhodium is distorted from ideal octahedral geometry as reflected in the bond parameters around rhodium. The $\mathrm{Rh}-\mathrm{P}(1)$ and $\mathrm{Rh}-\mathrm{Cl}(1)$ lengths are quite normal, and so are the $\mathrm{Rh}-\mathrm{O}(1), \mathrm{Rh}-\mathrm{O}(3)$, and $\mathrm{Rh}-$ $\mathrm{O}(4)$ distances. ${ }^{8}$ However, the $\mathrm{Rh}-\mathrm{O}(2)$ bond is slightly longer than the other three $\mathrm{Rh}-\mathrm{O}$ bonds and this elongation may be attributed to the trans effect of the $\mathrm{PPh}_{3}$ ligand. The $\mathrm{C}-\mathrm{O}, \mathrm{C}-\mathrm{N}$, and $\mathrm{N}-\mathrm{O}$ bond distances in the coordinated hydroxamate ligands indicate the expected electron delocalization (5) over the $\mathrm{O}-\mathrm{C}-\mathrm{N}-\mathrm{O}$ fragment. As all the [Rh$\left.\left(\mathrm{PPh}_{3}\right)\left(\mathrm{R}-\mathrm{R}^{\prime}\right)_{2} \mathrm{Cl}\right]$ complexes were synthesized similarly and as they display similar properties (vide infra), the other eight $\left[\mathrm{Rh}\left(\mathrm{PPh}_{3}\right)\left(\mathrm{R}-\mathrm{R}^{\prime}\right)_{2} \mathrm{Cl}\right]$ complexes are assumed to have the same stereochemistry as the $\left[\mathrm{Rh}\left(\mathrm{PPh}_{3}\right)(\mathrm{H}-\mathrm{H})_{2} \mathrm{Cl}\right]$ complex.

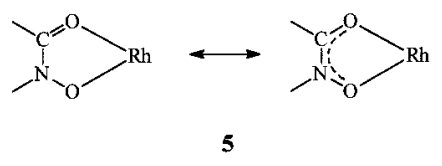

Magnetic susceptibility measurements show that all the $\left[\mathrm{Rh}\left(\mathrm{PPh}_{3}\right)\left(\mathrm{R}-\mathrm{R}^{\prime}\right)_{2} \mathrm{Cl}\right]$ complexes are diamagnetic, which corresponds to the +3 state of rhodium (low-spin $\mathrm{d}^{6}, S=0$ ) in these complexes. ${ }^{1} \mathrm{H}$ NMR spectra of the $\left[\mathrm{Rh}\left(\mathrm{PPh}_{3}\right)(\mathrm{R}-\right.$ $\left.\left.\mathrm{R}^{\prime}\right)_{2} \mathrm{Cl}\right]$ complexes were recorded in $\mathrm{CDCl}_{3}$ solution. The aromatic region $(6.5-8.5 \mathrm{ppm})$ of all the spectra is rather complex in nature due to overlap of signals arising from the two hydroxamate ligands and $\mathrm{PPh}_{3}$. Therefore assignment of individual signals to specific protons was not possible. However, the lack of any $C_{2}$ symmetry, as observed in the structure of $\left[\mathrm{Rh}\left(\mathrm{PPh}_{3}\right)(\mathrm{H}-\mathrm{H})_{2} \mathrm{Cl}\right]$, is clearly reflected in all the spectra, and intensity measurement of the signals corresponds well with the total number of aromatic protons present in the respective complexes. The two methyl signals in the $\left[\mathrm{Rh}\left(\mathrm{PPh}_{3}\right)\left(\mathrm{R}-\mathrm{CH}_{3}\right)_{2} \mathrm{Cl}\right]$ complexes are distinctly observed within $2.2-2.3 \mathrm{ppm}$. The NMR spectral data are

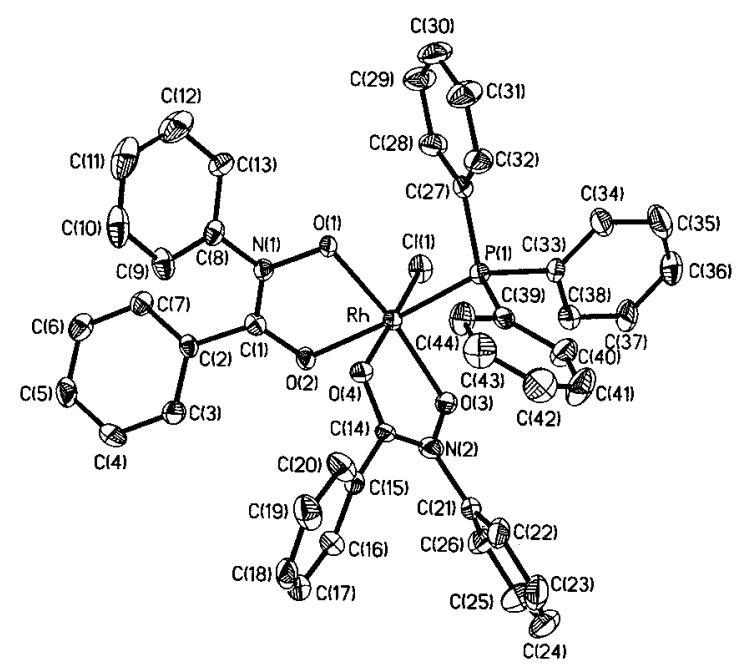

Figure 1. View of the $\left[\mathrm{Rh}\left(\mathrm{PPh}_{3}\right)(\mathrm{H}-\mathrm{H})_{2} \mathrm{Cl}\right]$ molecule.

Table 2. Selected Bond Parameters for $\left[\mathrm{Rh}\left(\mathrm{PPh}_{3}\right)(\mathrm{H}-\mathrm{H})_{2} \mathrm{Cl}\right] \cdot \mathrm{CH}_{3} \mathrm{CN}$

\begin{tabular}{lccr}
\multicolumn{5}{c}{ Bond Distances $(\AA)$} \\
$\mathrm{Rh}-\mathrm{Cl}(1)$ & $2.3251(13)$ & $\mathrm{O}(3)-\mathrm{N}(2)$ \\
$\mathrm{Rh}-\mathrm{O}(1)$ & $2.002(3)$ & $\mathrm{O}(4)-\mathrm{C}(14)$ & $1.374(4)$ \\
$\mathrm{Rh}-\mathrm{O}(2)$ & $2.114(3)$ & $\mathrm{C}(1)-\mathrm{C}(2)$ & $1.297(5)$ \\
$\mathrm{Rh}-\mathrm{O}(3)$ & $2.017(3)$ & $\mathrm{C}(14)-\mathrm{C}(15)$ & $1.465(5)$ \\
$\mathrm{Rh}-\mathrm{O}(4)$ & $2.013(3)$ & $\mathrm{N}(1)-\mathrm{C}(1)$ & $1.324(5)$ \\
$\mathrm{Rh}-\mathrm{P}(1)$ & $2.2473(13)$ & $\mathrm{N}(1)-\mathrm{C}(8)$ & $1.435(5)$ \\
$\mathrm{O}(1)-\mathrm{N}(1)$ & $1.387(4)$ & $\mathrm{N}(2)-\mathrm{C}(14)$ & $1.306(5)$ \\
$\mathrm{O}(2)-\mathrm{C}(1)$ & $1.274(5)$ & $\mathrm{N}(2)-\mathrm{C}(21)$ & $1.455(5)$ \\
\multicolumn{5}{c}{} \\
$\mathrm{O}(1)-\mathrm{Rh}-\mathrm{O}(4)$ & $90.58(12)$ & $\mathrm{O}(4)-\mathrm{Rh}-\mathrm{P}(1)$ & \\
$\mathrm{O}(1)-\mathrm{Rh}-\mathrm{P}(1)$ & $95.71(9)$ & $\mathrm{O}(4)-\mathrm{Rh}-\mathrm{Cl}(1)$ & $173.19(9)$ \\
$\mathrm{O}(1)-\mathrm{Rh}-\mathrm{Cl}(1)$ & $90.75(9)$ & $\mathrm{P}(1)-\mathrm{Rh}-\mathrm{Cl}(1)$ \\
$\mathrm{O}(1)-\mathrm{Rh}-\mathrm{O}(3)$ & $171.29(12)$ & $\mathrm{N}(1)-\mathrm{O}(1)-\mathrm{Rh}$ & $108.3(5)$ \\
$\mathrm{O}(1)-\mathrm{Rh}-\mathrm{O}(2)$ & $80.17(11)$ & $\mathrm{C}(1)-\mathrm{O}(2)-\mathrm{Rh}$ & $108.7(3)$ \\
$\mathrm{O}(2)-\mathrm{Rh}-\mathrm{P}(1)$ & $175.55(9)$ & $\mathrm{N}(2)-\mathrm{O}(3)-\mathrm{Rh}$ & $107.2(2)$ \\
$\mathrm{O}(2)-\mathrm{Rh}-\mathrm{Cl}(1)$ & $90.66(9)$ & $\mathrm{C}(14)-\mathrm{O}(4)-\mathrm{Rh}$ & $109.5(3)$ \\
$\mathrm{O}(3)-\mathrm{Rh}-\mathrm{P}(1)$ & $90.01(9)$ & $\mathrm{C}(1)-\mathrm{N}(1)-\mathrm{O}(1)$ & $119.1(4)$ \\
$\mathrm{O}(3)-\mathrm{Rh}-\mathrm{Cl}(1)$ & $95.73(9)$ & $\mathrm{C}(14)-\mathrm{N}(2)-\mathrm{O}(3)$ & $119.7(4)$ \\
$\mathrm{O}(3)-\mathrm{Rh}-\mathrm{O}(2)$ & $93.90(12)$ & $\mathrm{O}(2)-\mathrm{C}(1)-\mathrm{N}(1)$ & $120.6(4)$ \\
$\mathrm{O}(4)-\mathrm{Rh}-\mathrm{O}(3)$ & $82.34(12)$ & $\mathrm{O}(4)-\mathrm{C}(14)-\mathrm{N}(2)$ & $120.5(4)$ \\
$\mathrm{O}(4)-\mathrm{Rh}-\mathrm{O}(2)$ & $83.24(12)$ & &
\end{tabular}

therefore consistent with the compositions of the complexes. Infrared spectra of the $\left[\mathrm{Rh}\left(\mathrm{PPh}_{3}\right)\left(\mathrm{R}-\mathrm{R}^{\prime}\right)_{2} \mathrm{Cl}\right]$ complexes are qualitatively very similar. Each complex shows many sharp bands of different intensities below $1700 \mathrm{~cm}^{-1}$. Comparison with the spectrum of $\left[\mathrm{Rh}\left(\mathrm{PPh}_{3}\right)_{3} \mathrm{Cl}\right]$ shows, in addition to some common vibrations, many new bands in the spectra of the $\left[\mathrm{Rh}\left(\mathrm{PPh}_{3}\right)\left(\mathrm{R}-\mathrm{R}^{\prime}\right)_{2} \mathrm{Cl}\right]$ complexes. Of these new bands, the two observed near 1530 and $1514 \mathrm{~cm}^{-1}$ are attributed to the $v_{\mathrm{CO}}$ vibrations and the one near $1250 \mathrm{~cm}^{-1}$ is assigned to the $v_{\mathrm{NO}}$ vibration. Two close bands, observed near 1346 and $1325 \mathrm{~cm}^{-1}$ in all the complexes, are probably due to the $v_{\mathrm{CN}}$ vibrations. All these vibrational energies are much shifted relative to the free ligand, and the observed shift is attributable to the resonance possible in the coordinated hydroxamate ligands (5).

The $\left[\mathrm{Rh}\left(\mathrm{PPh}_{3}\right)\left(\mathrm{R}-\mathrm{R}^{\prime}\right)_{2} \mathrm{Cl}\right]$ complexes are soluble in common polar organic solvents such as acetonitrile, dichloromethane, chloroform, acetone, etc., producing intense orange solutions. Electronic spectra of these complexes were recorded in acetonitrile solution. Each complex shows intense absorptions in the visible and ultraviolet region (Table 3). 


\section{NOTE}

Table 3. Electronic Spectral and Cyclic Voltammetric Data

\begin{tabular}{lcc}
\hline \multicolumn{1}{c}{ Compd } & $\begin{array}{c}\text { electronic spectral data: } \\
\lambda_{\max } / \mathrm{nm}\left(\epsilon / \mathrm{M}^{-1} \mathrm{~cm}^{-1}\right)^{a}\end{array}$ & $\begin{array}{c}\text { cyclic voltammetric } \\
\text { data: }{ }^{a, b} E / \mathrm{V} \text { vs SCE }\end{array}$ \\
\hline$\left[\mathrm{Rh}\left(\mathrm{PPh}_{3}\right)(\mathrm{H}-\mathrm{H})_{2} \mathrm{Cl}\right]$ & $424^{c}(1100), 326^{c}(6500)$, & $1.25,{ }^{d}-0.52^{e}$ \\
& $262^{c}(35800)$ & \\
{$\left[\mathrm{Rh}\left(\mathrm{PPh}_{3}\right)(\mathrm{Cl}-\mathrm{H})_{2} \mathrm{Cl}\right]$} & $440^{c}(800), 334^{c}(5900)$, & $1.27,{ }^{d}-0.53^{e}$ \\
& $262^{c}(33000)$ & \\
{$\left[\mathrm{Rh}\left(\mathrm{PPh}_{3}\right)\left(\mathrm{NO}_{2}-\mathrm{H}\right)_{2} \mathrm{Cl}\right]$} & $408^{c}(3800), 270^{c}(42900)$ & $1.34,{ }^{d}-0.59^{e}$ \\
{$\left[\mathrm{Rh}\left(\mathrm{PPh}_{3}\right)\left(\mathrm{H}-\mathrm{CH}_{3}\right)_{2} \mathrm{Cl}\right]$} & $434^{c}(1000), 332^{c}(6000)$, & $1.23,{ }^{d}-0.65^{e}$ \\
{$\left[\mathrm{Rh}\left(\mathrm{PPh}_{3}\right)\left(\mathrm{Cl}-\mathrm{CH}_{3}\right)_{2} \mathrm{Cl}\right]$} & $436^{c}(900), 336^{c}(6400)$, & $1.25,{ }^{d}-0.61^{e}$ \\
& $262^{c}(39700)$ & \\
{$\left[\mathrm{Rh}\left(\mathrm{PPh}_{3}\right)\left(\mathrm{NO}_{2}-\mathrm{CH}\right)_{2} \mathrm{Cl}\right]$} & $360^{c}(5500), 266^{c}(34000)$ & $1.33,{ }^{d}-0.51^{e}$ \\
{$\left[\mathrm{Rh}\left(\mathrm{PPh}_{3}\right)(\mathrm{H}-\mathrm{Cl})_{2} \mathrm{Cl}\right]$} & $428^{c}(1200), 340^{c}(8200)$, & $1.28,{ }^{d}-0.49^{e}$ \\
& $266^{c}(38400)$ \\
{$\left[\mathrm{Rh}\left(\mathrm{PPh}_{3}\right)(\mathrm{Cl}-\mathrm{Cl})_{2} \mathrm{Cl}\right]$} & $438^{c}(1300), 336^{c}(9200)$, & $1.30,{ }^{d}-0.64^{e}$ \\
& $262^{c}(53200)$ & \\
{$\left[\mathrm{Rh}\left(\mathrm{PPh}_{3}\right)\left(\mathrm{NO}_{2}-\mathrm{Cl}\right)_{2} \mathrm{Cl}\right]$} & $446^{c}(800), 302^{c}(37400)$ & $1.37,{ }^{d}-0.54^{e}$
\end{tabular}

${ }^{a}$ In acetonitrile. ${ }^{b}$ Supporting electrolyte, TBAP; scan rate $50 \mathrm{mV} \mathrm{s}^{-1}$. ${ }^{c}$ Shoulder. ${ }^{d} E_{\mathrm{pa}}$ value. ${ }^{e} E_{\mathrm{pc}}$ value.

The absorptions in the ultraviolet region are assignable to transitions within the ligand orbitals, and those in the visible region are probably due to allowed charge-transfer transitions.

Electrochemical properties of the $\left[\mathrm{Rh}\left(\mathrm{PPh}_{3}\right)\left(\mathrm{R}-\mathrm{R}^{\prime}\right)_{2} \mathrm{Cl}\right]$ complexes were studied in acetonitrile solution $(0.1 \mathrm{M}$ TBAP) by cyclic voltammetry. Each complex shows an oxidative response within 1.23 to $1.37 \mathrm{~V}$ versus SCE and a reductive response within -0.49 to $-0.65 \mathrm{~V}$ versus SCE. Voltammetric data are given in Table 3. The oxidative response is assigned to the rhodium(III)-rhodium(IV) oxidation. One-electron stoichiometry of this response was established by comparing its current height $\left(i_{\mathrm{pa}}\right)$ with that of standard ferrocene/ferrocenium couple under identical experimental conditions. The oxidative response is irreversible in nature (at scan rate of $50 \mathrm{mV} \mathrm{s}^{-1}$ ) which indicates that $\left[\mathrm{Rh}^{\mathrm{IV}}\left(\mathrm{PPh}_{3}\right)\left(\mathrm{R}-\mathrm{R}^{\prime}\right)_{2} \mathrm{Cl}\right]^{+}$, produced on the anodic scan, is unstable and undergoes rapid chemical transformation. The reduction wave, corresponding to reduction of $\left[\mathrm{Rh}^{\mathrm{IV}}\left(\mathrm{PPh}_{3}\right)(\mathrm{R}-\right.$ $\left.\left.\mathrm{R}^{\prime}\right)_{2} \mathrm{Cl}\right]^{+}$, is only observed at higher scan rates $(>200 \mathrm{mV}$ $\left.\mathrm{s}^{-1}\right)$. The metal-centered oxidation potential in these [Rh$\left.\left(\mathrm{PPh}_{3}\right)\left(\mathrm{R}-\mathrm{R}^{\prime}\right)_{2} \mathrm{Cl}\right]$ complexes varies with the electronwithdrawing character of the two substituents ( $R$ and $\left.R^{\prime}\right)$ in the hydroxamate ligand, and it is interesting to note that the substituents, which are seven bonds away from the metal center, can still influence the metal-centered oxidation potential. The reductive response is assigned to the rhodium(III)-rhodium(II) reduction. This reduction is also irreversiable at scan rate of $50 \mathrm{mV} \mathrm{s}^{-1}$ and even at higher scan rates. Potential of this reduction does not show any systematic variation with the substituents ( $R$ and $\left.R^{\prime}\right)$. The cyclic voltammetric experiments thus indicate that the trivalent state of rhodium is quite stable in these $\left[\mathrm{Rh}\left(\mathrm{PPh}_{3}\right)\left(\mathrm{R}-\mathrm{R}^{\prime}\right)_{2} \mathrm{Cl}\right]$ complexes, while the higher and lower oxidation states are not.

\section{Conclusions}

This study shows that, in their reaction with transition metal ions, the $N$-phenylbenzohydroxamic acids may play two different roles depending on the oxidation state of the metal ion. This is well manifested in their reaction with rhodium(I) and rhodium(III). For rhodium(I) the $N$-phenylbenzohydroxamic acids serve as oxidizing agents, they oxidize rhodium(I) to rhodium(III), and at the same time themselves are reduced to the corresponding amides. With rhodium(III), however, the same hydroxamic acids only undergo complexation in the usual fashion.

Acknowledgment. Financial assistance received from the Department of Science and Technology, New Delhi (Grant No. SP/S1/F33/98), and the Council of Scientific and Industrial Research, New Delhi [Grant No. 01(1675)/00/ EMR-II], is gratefully acknowledged. The authors thank Professor S. Lahiri of the Department of Organic Chemistry, Indian Association for the Cultivation of Science, Kolkata, India, for her help, the RSIC at Central Drug Research Institute, Lucknow, India, for the $\mathrm{C}, \mathrm{H}, \mathrm{N}$ analysis data, and the Bose Institute, Kolkata 700054, India, for NMR spectral measurements. Sincere thanks are also due to the reviewers for their critical comments and suggestions, which have been of great help during revision of the manuscript.

Supporting Information Available: Crystal information for $\left[\mathrm{Rh}\left(\mathrm{PPh}_{3}\right)(\mathrm{H}-\mathrm{H})_{2} \mathrm{Cl}\right] \cdot \mathrm{CH}_{3} \mathrm{CN}$ in CIF format, a table containing analytical data for the complexes, and a figure showing the cyclic voltammogram of one representative complex. This material is available free of charge via the Internet at http://pubs.acs.org.

IC0106930 